high-priority testing. And if the decision is the opposite, maximum effort should be deployed to reduce the blatant inequalities that result from distant schooling.

Moreover, people of working age but with a high-risk profile for COVID-19 should be exempted from the obligation to return to the workplace. The different target groups would need to be defined transparently, according to each country's specific demographic and socio-economic context, and with the active involvement of the different stakeholders so as to maximize the social acceptance that will be key to successful implementation. In countries in which there are issues of financial access to healthcare, the cost of testing would need to be subsidized so that cost is not an obstacle to its wide application.

While at first only immunized but virus-free people may go back to their normal lives, when the pandemic subsides, gradually younger people - age being a key risk factor - who are virus free but not immunized may be considered too. Priority for testing such low-risk people should be given to those operating in sectors considered essential. Such an approach would slowly build up 'herd immunity', which would reduce the intensity of future waves of the pandemic. The goal should be for everyone to eventually rejoin their normal lives and thereby avoid the stigma of two 'types' of citizens: those who are immunized and risk free, and those who are not. In any case, this risk is not permanent, since it will be much reduced once a cure and/or a vaccine is (are) found.

Such a combined strategy would allow countries to progressively shift from collective and massive social-distancing measures to systematic testing of symptomatic cases, isolation of COVID19-positive people, and identification and quarantine of their exposed contacts, in parallel with the release of immune people from any confinement measure. Quantitative mathematical modeling should be used as soon as possible to ensure that the proposed sets of actions would be safe, to make certain that the level of transmission and severe cases remain below the health system's capacity, to fine-tune the timing and phasing of actions, and to inform the decision on target groups that will be gradually released from confinement.

This would make it possible to reconcile the advantages of the two opposing strategies that have been proposed so far: the strategy of global containment of the population, which is economically and socially costly, and the strategy exclusively based on 'herd immunity', which potentially involves a very substantial human cost if done too fast at an early stage of the pandemic. However, the successful management of this crisis will depend mainly on the support of the population. Allowing some types of workers to return to work while preventing others from doing so is liable to cause tensions aroused by feelings of positive or negative discrimination, and these feelings may actually differ depending upon whether the worker is a wage earner or an independent worker or entrepreneur. This dimension has to be thought over, and the rationale of any measure must be carefully explained to the population. The same applies to the questions of how to organize the quarantine of infected people to avoid a resurgence of the pandemic, and how to manage inequalities in access to health care. Citizen ownership will be essential to ensure that solidarity prevails over discrimination.

Marius Gilbert', Mathias Dewatripont ${ }^{1}$, Eric Muraille (D) 1,2, Jean-Philippe Platteau ${ }^{2}$ and Michel Goldman ${ }^{1 凶}$

${ }^{1}$ Université Libre de Bruxelles, Brussels, Belgium.

${ }^{2}$ Université de Namur, Namur, Belgium.

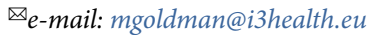

Published online: 14 April 2020

https://doi.org/10.1038/s41591-020-0871-y

References

1. Case, A. \& Deaton, A. Deaths of Despair and the Future of Capitalism (Princeton University Press, 2020).

2. Dewatripont, M., Goldman, M., Muraille, E. \& Platteau, J.-P. VOX CEPR Policy Portal https://voxeu.org/article/ rapidly-identifying-workers-who-are-immune-covid19-and-virus-free-priority-restarting-economy (23 March 2020).

The authors declare no competing interests.

\title{
Biomedical research: lessons from the last decade's crisis and austerity-stricken small countries for the current COVID-19-related crisis
}

The 2007-2008 economic crash has had long-lasting effects on Greece's biomedical research landscape. It has exposed a gap in support for countries that are classified as high income but are living under austerity measures. A new model is needed for optimal utilization of the intellectual and natural resources that such countries can offer to improve the global research landscape.

\section{George P. Chrousos, Alexios-Fotios A. Mentis and Efthimios Dardiotis}

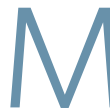

any countries were afflicted by the most recent decade-long financial crisis and its accompanying austerity measures. In Greece, Spain, Portugal and other countries, funding scarcity has greatly impeded the performance of expensive biomedical research in particular ${ }^{1}$. This field was particularly hit because the crisis took place while there was, at the same period, an explosion of costly, resource-expensive studies of biological pathways, precision medicine, big-data science, super-resolution imaging, robotics and high-throughput experimental technologies. 
Table 1 | Natural resources for life and health sciences

Examples of studies in Greece

Molecular case series

Cardiac problems (Naxos disease)

Genome versus exposome studies

Islands' centenarians ('Ikaria blue zone') marked by close adherence to a Mediterranean diet and good stress management

\section{Mechanistic studies}

Genetic blood disorders

Examples of studies on a global scale

\section{Ethnic groups}

Iceland's population genetics and genomics analyses (including the deCODE genetics project)

Uganda Genome Resource

Metagenomic analyses in Africa

Religious groups

Amish in the USA

\section{Table 2 | Natural resources for biotechnology}

Studies

Ref.

Submarine biotechnology

Hellenic Volcanic Arc, described as the largest 'submarine volcanic ecosystems, a significant resource of novel genes and pathways with potential biotechnological applications'

\section{Archaeogenomics}

Archaeogenomics studies on the roots of civilization around the Mediterranean Sea, and on the development of farming

\section{Climate change}

Cyprus as a regional hub ('sensitive antenna') for climate change in the Eastern Mediterranean region

There are several long-standing programs that support research in low- and middle-income countries. For instance, such countries could benefit from the Research4Life programs AGORA, Hinari, OARE, ARDI and GOALI, or they could be entitled to request waivers for full tuition fees for their graduate students in leading foreign academic institutions. These countries face fundamental difficulties of their own, and such programs are sorely needed. In contrast, when small, high-income, developed countries are stricken by decreases in their gross domestic product, they cannot benefit from the developmental policies and remedial programs available to developing countries. Therefore, they could be fairly described as 'research resourcepoor countries'.

Should developed but crisis-stricken countries receive an extramural research boost as an act of solidarity and science diplomacy, or, instead, should they consider themselves a lost case? Using our country, Greece, as an example, we argue for a third alternative, one that many other countries around the world would find applicable now and in the future: to look locally for 'attractive niches' and 'hidden pearls' of added value to global biomedical research (Table 1 and 2). This notion becomes more important during the post-austerity years, given Greece's situation as part of a broader policy gap, in the sense that while a remedial mode for middleand low-income countries exists, there is not one suitable for small, high-income, research resource-poor countries. Such support is especially important for Greece and many other equally unprepared or not-well-equipped countries, not only as a consequence of the recent austerity period but also because another economic breakdown will probably follow the current COVID-19 pandemic, which will probably impose fiscal budget shifts from research (often considered a luxury during an epidemic, unless it is epidemic related) to the health sector.

Greece, like many other countries, has become a place of remarkable contradiction. It has a large number of well-trained scientists, but the vast majority of them are unemployed, under-employed or seeking work abroad. Policymakers have promised to address several long-standing structural problems in research funding ${ }^{1}$, yet the total spending on research and development remains quite limited ${ }^{2}$. In particular, research funding in Greece has been consistently limited, especially for basic research, and of note, it has been unequally distributed, because of the following: (a) barely existent structural changes oriented toward innovation; (b) lack of matching between university curricula and the skills required by the generally meager industry; (c) indecisive policies on research priorities (leading, in turn, to the disintegration of strong research groups); (d) a lack of consideration of cost-effectiveness during policy formulation; (e) a vast, albeit improving bureaucracy; (f) high corruption indices (inversely linked to innovation performance); (g) a lagging behind in alignment with the goals of the United Nation's Sustainable Development Agenda and those of the World Health Organization (for example, supporting research on traditional, environmentally burdensome energy forms instead of long-term planning for the upcoming climate crisis); and (h) frequent political party-guided non-meritocratic science policies. These conditions intensified during the austerity years, which led research performance to even lower capacities ${ }^{3-10}$.

Despite the conditions described above, Greece has managed to survive scientifically and to score high in terms of the academic productivity of its scientists, such as publication metrics and citations, in part because of the strong mindset of its human capital—namely, its stamina for research despite adversities and compliance with the concept of the Greek 'philotimon', which describes a set of several human virtues. This is in contrast to a relative paucity in filings for new patents, based on the locally prevailing idea of considering science purely as a search for the truth that is incompatible with generation of personal profit.

In light of such traits, it should be recognized that research resource-poor countries, by their own nature, cannot contribute equally to highly complicated, costly projects that require advanced expensive experimentation; thus, mutual 
respect and appropriately balanced acknowledgment of intellectual properties and co-authorships in inter-country collaborations are crucial for success. Treating these countries through an equity perspective rather than an equality perspective is warranted at all times, and even more so during epidemics. Furthermore, diversity issues that embrace the inclusion of resource-poor countries in the eligibility criteria for major international grant proposals should be advocated. Bold ideas could potentially emerge in every research corner of the world; these, coupled with the possibility of addressing complex experiments to be conducted on a collaborative or outsourcing basis, could potentially yield truly impactful results ${ }^{11}$. Building up scientific collaborations, in which research resource-poor countries could offer a competitive advantage (e.g., based on their scientists and research niches), can lead potentially to scientific breakthroughs. This notion could strengthen science equity in the global research agenda. Particularly in light of recent actions in other diversity-inclusive policies (e.g., gender equity ${ }^{12}$ ), publishers of high-caliber journals, including multidisciplinary ones, should be encouraged to develop country diversity indices, as the importance of publication metrics cannot be overstated.

In addition, young scientists could be involved in exchange programs between research resource-rich countries and resource-poor countries; notably, as part of 'brain-regain' efforts (such as the so-called '2017 Hellenic Pasteur Institute Declaration' in Greece, a document signed by notable scientists of the country and its diaspora to advocate for political interventions on 'brain regain'), after completion of their studies in the former countries, they could be asked to return to secure jobs in their home countries, which would allow them to transfuse the knowledge obtained abroad into new regional research hubs. On the basis of appropriate strategies, support for young scientists should include protected and sustained, albeit competitive, funding from grant applications and the establishment of a solid formal network of collaborations with resource-rich countries ${ }^{13}$. Doing so can be the best antidote to 'brain drain' and 'brain deficit' (terms in ref. ${ }^{14}$ ). We call this approach the 'twinning of laboratories', akin to the twinning of towns, which, far from 'scientific colonialism', could be mutually beneficial in various scientific fields (e.g., research on endemic infections and local rare diseases, cultural anthropology and so on).

The examples described above, which stem from a range of research fields, hopefully illustrate how a small, resource-poor country's well-educated research force and rich natural diversity represent a model for dealing with the global research agenda during crises and austerity times. Providing resources to local and foreign collaborating scientists should be sustained, and quality checkpoints assessing alignment with international scientific standards (including bioethical, biosecurity, biosafety and biobanking principles and guidelines, as well as commonly accepted standards of reproducibility, such as integrity, validation methodologies and data openness ${ }^{15}$ ) should continue to be met. Ultimately, these examples will pave the way for other small countries to look into their own human and natural resources to develop their competitive advantages in the emerging economically harsh global era.

\section{George P. Chrousos ${ }^{1,2,6 凶,}$ \\ Alexios-Fotios A. Mentis (D) 3,4,6 and Efthimios Dardiotis (iD) 5}

${ }^{1}$ University Research Institute of Maternal and Child Health \& Precision Medicine, National and Kapodistrian University of Athens, 'Aghia Sophia' Children's Hospital, Athens, Greece. ${ }^{2}$ UNESCO Chair on Adolescent Health Care, National and
Kapodistrian University of Athens, 'Aghia Sophia' Children's Hospital, Athens, Greece. ${ }^{3}$ Public Health Laboratories, Hellenic Pasteur Institute, Athens, Greece. ${ }^{4}$ Department of Microbiology, University Hospital of Larissa, University of Thessaly, Larissa, Greece. ${ }^{5}$ Department of Neurology, University Hospital of Larissa, University of Thessaly, Larissa, Greece. ${ }^{6}$ These authors contributed equally: George P. Chrousos, Alexios-Fotios A. Mentis.

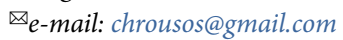

Published online: 17 April 2020 https://doi.org/10.1038/s41591-020-0859-7

\section{References}

1. Mentis, A. A. \& Chrousos, G. P. Eur. J. Clin. Invest. 49 e13167 (2019).

2. Press, W. H. Science 342, 817-822 (2013).

3. Allen-Ramdial, S.-A. A. \& Campbell, A. G. Bioscience 64, 612-618 (2014).

4. Kollias, G. \& Lambris, J. D. Nat. Immunol. 16, 1206-1208 (2015).

5. Nature 572, 153 (2019).

6. Featherstone, K. Nature 518, 167 (2015).

7. Synolakis, C. \& Foteinis, S. Nature 461, 167 (2009).

8. Nature 409, 545 (2001).

9. Herrmann, B. \& Kritikos, A. S. I. Z. A. J. Eur. Labor Studies 2, 14 (2013).

10. Mastellos, D. C. et al. Nat. Immunol. 20, 1409-1413 (2019).

11. Smith, D. R. EMBO Rep. 16, 14-16 (2015).

12. Silver, J. K. Br. Med. J. 367, 15888 (2019).

13. Ahmed, A., Daily, J. P., Lescano, A. G., Golightly, L. M. \& Fasina, A. Am. J. Trop. Med. Hyg 102, 494-496 (2020).

14. Ioannidis, J. P. FASEB J. 18, 936-939 (2004).

15. Amann, R. I. et al. Science 363, 350-352 (2019).

16. Zhang, Z. et al. J. Clin. Invest. 125, 1708-1712 (2015).

17. Pietri, P., Papaioannou, T. \& Stefanadis, C. Nature 544, 416 (2017).

18. Higgs, D. R., Engel, J. D. \& Stamatoyannopoulos, G. Lancet 379, 373-383 (2012).

19. Ebenesersdóttir, S. S. et al. Science 360, 1028-1032 (2018).

20. Gurdasani, D. et al. Cell 179, 984-1002.e1036 (2019).

21. Brewster, R. et al. Trends Microbiol. 27, 824-835 (2019).

22. Xu, H. et al. Diabetes 66, 2054-2058 (2017).

23. Oulas, A. et al. Environ. Microbiol. 18, 1122-1136 (2016).

24. Mathieson, I. et al. Nature 555, 197-203 (2018).

25. Makri, A. Nature 559, 15-16 (2018).

Acknowledgements

The opinions expressed herein may not necessarily reflect those of the institutions with which the authors are affiliated. Part of this Comment was presented at a meeting on science policy and its future that took place in Athens, Greece (12 September 2019).

Competing interests

G.P.C. served as vice-president and member of the Greek National Council of Research and Technology/Innovation (2010-2015). 